\title{
The interaction of international institutions from a social network perspective
}

\author{
Tobias Böhmelt • Gabriele Spilker
}

\begin{abstract}
The literature increasingly acknowledges that international institutions do not exist in isolation, but regularly interact with each other. This interplay might induce influence, affecting institutions' development and performance. The following research adds to this debate by systematically analyzing the quantitative evidence on how institutional interaction drives institutional design from a network perspective. Using dyadic cross-sectional data on international environmental agreements in 1952-2000, the authors find support for their theoretical argument that regimes' similarity in design as captured by their degree of legalization strongly depends on institutions' interaction. However, while "soft law" disseminates between regimes that are well connected through direct or indirect links, this does not apply to "hard law." The authors explain this divergence with states" concerns about binding-law commitments and sovereignty costs associated with the latter. This research may have important implications for studies of international institutions and of network analysis in general.
\end{abstract}

Keywords Global environmental governance · Institutional interaction · International institutions $\cdot$ Legalization $\cdot$ Social network analysis

T. Böhmelt $(\bowtie)$

Department of Government, University of Essex, Wivenhoe Park, Colchester CO4 3SQ, UK

e-mail: tbohmelt@essex.ac.uk; tobias.boehmelt@ir.gess.ethz.ch

T. Böhmelt · G. Spilker

Center for Comparative and International Studies, ETH Zürich, Haldeneggsteig 4, 8092 Zurich,

Switzerland

e-mail: gabriele.spilker@ir.gess.ethz.ch

G. Spilker

Department of Political Science, University of Salzburg, Kapitelgasse 4-6, 5020 Salzburg, Austria 


\section{Introduction}

International institutions do not exist in isolation from each other, but are situated in a broader network of regimes, in which they can be the source or the target of influences that affect an institution's development or effectiveness. ${ }^{1}$ The literature increasingly acknowledges this phenomenon of "institutional interaction," and primarily focuses on whether it actually shapes the performance of institutions (e.g., Oberthür and Gehring 2006; Gehring and Oberthür 2009; see also Stokke 2001; Young 2002; Oberthür and Stokke 2011; Ovodenko and Keohane 2012). One of the main claims in this literature is that information on working procedures, regulations, or performance in general can spread through common linkages between a source and a target institution, thereby influencing the performance of the latter regime. However, it is usually an empirical question whether regime interaction leads to synergetic effects or rather hampers effectiveness.

This literature furthered our understanding of international institutions and their effectiveness within global governance substantially. However, the nearly exclusive focus on regimes' performance occurred at the expense of accounting for another important facet: the previous work does not explicitly examine whether or how regime design is affected by institutional interaction. We believe that this constitutes a crucial gap in the literature. For example, Miles et al. (2002) demonstrate that institutional design strongly influences the performance of regimes. When subscribing to this, an important aspect of institutional effectiveness, i.e., a factor that functions as an intervening variable remains uncovered if institutional interaction does indeed affect treaty design. Consequently, if institutional interaction drives both the design and the effectiveness of international regimes, the previous literature with its sole focus on effectiveness may have overlooked a central facet of the institutional-interaction nexus. ${ }^{2} \mathrm{We}$ seek to contribute to this debate by systematically analyzing how the interaction between international institutions affects their design and, in particular, their degree of design similarity.

As a first innovation, we study institutional interaction from a social network perspective (see also Ward 2006; Dorussen and Ward 2008; Hafner-Burton et al. 2009). Based on this approach, two institutions will share more information if they are strongly linked with each other, which we see as important for explaining the degree of institutional similarity between two interacting institutions. In contrast, if two institutions are not or only remotely linked to each other, information on institutional design should not transfer that easily. Hence, a reasonable expectation is that two well-connected institutions are more likely to display similarity in their design characteristics. However, we argue that this relationship depends on the type of institutional design in place. This constitutes our second contribution to the literature.

In particular, we define design, both theoretically and empirically, either in the form of "soft law" or "hard law" (Abbott et al. 2000; Abbott and Snidal 2000; see also Shaffer and Pollack 2010, 2011). This distinction is based on the three dimensions of legalization typically found in the literature, i.e., obligation, precision, and delegation (Abbott et al.

\footnotetext{
"We use the terms "(international) institution," "regime," and "treaty" interchangeably. We also treat "performance" and "effectiveness" equally.

2 Skjærseth et al. (2006) is the only exception in this regard. We elaborate below how we build on and intend to extend this study.
} 
2000; Abbott and Snidal 2000). ${ }^{3}$ States generally face a tradeoff when deciding between the implementation of soft or hard law (Fearon 1998; Rosendorff and Milner 2001; Rosendorff 2005; see also Downs et al. 1996; Bernauer et al. 2013; Spilker and Koubi 2012). On the one hand, soft-law design is likely to allow for flexibility and to impose less sovereignty costs on (potential) member states (see also Slaughter 2004). That said, the most crucial weakness of soft law seems to be that it cannot be enforced or does not provide clear targets. On the other hand, hard law imposes obligatory and precise commitments. This could make institutions potentially better suited to solve the underlying problem, although hard law should be less attractive in the first place, because of the high sovereignty costs it inflicts upon members (see also Slaughter 2004; Skjærseth et al. 2006). When combining these two strands of the literature, we contend that regime interaction as conceptualized via ties and linkages from a network perspective should only induce design similarity between two institutions that are well connected if we study soft law. Conversely, institutional interplay is unlikely to lead to design similarity in the case of hard law. As elaborated below, this is because of obligatory commitments and sovereignty costs imposed on states that should outweigh any concerns regarding the enforceability of institutional targets.

The empirical section using network analysis to study the spread of design similarity between 195 international environmental treaties in 1952-2000 supports our theory. We are able to show that those treaties that have many (direct and indirect) links through member states do indeed display design similarity in the case of soft law, but not in case of hard law. To the best of our knowledge, this study represents the first quantitative indication that regime interaction through membership ties can affect regime design and not only regime performance, as typically studied in the literature. ${ }^{4}$ While relying on this quantitative setup clearly has the advantage that we are able to depict a general pattern under which conditions institutional interaction leads to design similarity, it is outside the scope of this article to provide evidence on the micro-mechanisms of how these membership ties lead to design similarity.

The paper proceeds as follows. The next section summarizes the existent literature on institutional interaction, which allows us to outline more thoroughly the research gap we seek to address. Due to our approach, which highlights that information about design characteristics might flow through ties connecting regimes in the network of international treaties, we also introduce and discuss the core concepts of network analysis. Afterward, we combine institutional interaction, network analysis, and treaty design in the form of either hard or soft law, and hypothesize that the impact of institutional interaction depends on the type of the design in question. The succeeding sections present our research design, the empirical analysis, as well as our results. ${ }^{5} \mathrm{We}$ finish the article with a discussion of our findings, and suggest implications for future studies and policymakers.

\footnotetext{
${ }^{3}$ Regime design can refer to more aspects than those under study here, such as the incorporation and design of dispute settlement mechanisms, the form of decision making, etc. However, our choice to understand design in terms of hard versus soft law is grounded in the fact that a major strand of the literature, to which we strive to contribute to, focuses on this particular aspect of regime design (Goldstein and Martin 2000; Skjærseth et al. 2006; Bernauer et al. 2013).

4 For recent overviews, see Oberthür and Stokke (2011) or Oberthür and Gehring (2011).

${ }^{5}$ We also conducted a series of robustness checks, which we discuss in the online appendix or briefly refer to below.
} 


\section{An overview of the interaction of international institutions in the literature}

When establishing a regime, states may rely on existing institutions from the same or even other issue areas as "blueprints" (Stokke 2001; Oberthür and Gehring 2006; Gehring and Oberthür 2009; Hofmann 2010; Oberthür and Stokke 2011; Ovodenko and Keohane 2012). Gehring and Oberthür (2009: 127) define this process of one institution influencing another regime as institutional interaction or interplay, i.e., a mechanism by which "one institution (the source institution) affects the development or performance of another institution (the target institution)" (see also Stokke 2001; Oberthür and Gehring 2006, 2011; Oberthür and Stokke 2011; Ovodenko and Keohane 2012). In the context of our study, this mechanism implies that the design of the source institution influences the perceptions, preferences, and behavior of the member states. In turn, common state members between the source and a target institution allow that information on the implications of the design choices in the source institution spread to the target institution, thereby influencing the latter's design.

Gehring and Oberthür (2009; see also Oberthür and Gehring 2006) list several causal mechanisms through which institutional interplay can occur. Next to interaction through commitment, behavioral interaction, and impact-level interaction, the most relevant mechanism for this research works through "cognitive interaction" that is based on institutional learning (Gehring and Oberthür 2009: 132; see also Ovodenko and Keohane 2012: 523): members of one regime use their experience with and information about one institution's development or performance for affecting another institution. We briefly list the steps according to which cognitive interaction evolves here, but refer the reader to Oberthür and Gehring (2006: 35ff, 2011: 35ff; see also Gehring and Oberthür 2009: 132f) for a detailed discussion of this mechanism: first, the source institution generates new information, e.g., an institutional arrangement that seeks to address and solve a particular regulatory problem; second, the member states of the source institution and, more precisely, their behavior, perceptions, and preferences are affected by this change and feed the information into the decision-making process of the target institution; third, this information then changes the preferences of the member states of the target institution before, and fourth, this modification influences the target institution as such.

Gehring and Oberthür (2009: 134) illustrate this via the compliance system of both the Montreal Protocol on Substances that Deplete the Ozone Layer (Montreal Protocol) and the Kyoto Protocol to the United Nations Framework Convention on Climate Change (UNFCCC). When negotiating the latter, those states that were already involved in the former seemed to have learned from their positive experiences with the Montreal Protocol's compliance procedure. In turn, states agreed to implement the same institutional design in the Kyoto Protocol (see also Oberthür 2001: 360f). However, this examination of the impact of institutional interaction on regime design seems to constitute an exception rather than the rule in the literature. Most studies exclusively analyze if and how institutional interaction affects the performance of a target regime (Brosig 2011; Grilo 2011; Hofmann 2010; Jinnah 2010; Stokke 2001; see also Skjærseth et al. 2006). While our research builds on the theoretical insights from this earlier work, particularly with regard to the cognitive interaction mechanism, we are actually interested in a different aspect of institutional interaction, i.e., how it influences the design of international institutions or, specifically, their degree of design similarity.

With the exception of Skjærseth et al. (2006), we are not aware of any other study that explicitly examines how institutional interaction can result in the dissemination of soft and hard law (Abbott et al. 2000; Abbott and Snidal 2000). Via three case studies, these scholars show that soft-law and hard-law institutions can interact in a way that leads soft- 
law regimes to adapt more hard-law characteristics and vice versa. Although we rely on Skjærseth et al. (2006) for developing the argument in the following, our study differs from these authors in three ways. First, Skjærseth et al. (2006) differentiate between soft and hard law solely according to the obligation criterion, i.e., whether a treaty's rules can be enforced on its members. Still, especially the work by Abbott et al. (2000); see also Abbott and Snidal 2000) emphasizes that both hard and soft law require more nuanced concepts than only obligation. This rationale led to the three dimensions of legalization, i.e., obligation, precision, and delegation. Accordingly, our study seeks to capture all the three dimensions theoretically and empirically.

Second, Skjærseth et al. (2006) focus on what the literature coined "vertical interaction," i.e., the interplay between institutions at different levels of organization (Young 2002; see also Oberthür and Gehring 2006; Gehring and Oberthür 2009; Stokke 2001). While this type constitutes an important facet within the context of institutional interplay, it nevertheless overlooks the concept of "horizontal interaction," i.e., institutional interaction at similar levels of organization, which is likely to be equally important (Young 2002; Oberthür and Gehring 2006; Gehring and Oberthür 2009; Stokke 2001). We concentrate on horizontal interaction by studying how different international treaties at the same, i.e., global, level affect each other.

Third, as indicated, Skjærseth et al. (2006) employ a qualitative case-study design for the empirical test of their theory. The insights on the causal mechanisms gained by these authors' three cases of marine pollution, transboundary air pollution, and fisheries subsidy control fruitfully complement our study. Yet, the generalizability of Skjærseth et al.'s (2006) results may be limited. In order to address this, we use a data sample that covers all multilateral environmental treaties, thereby ensuring that our study is likely to have a broad empirical scope.

\section{Information flows through networks: network analysis as a tool for the study of institutional interaction}

This section outlines an approach that may facilitate our understanding of how influences flow between international institutions. The concept of cognitive interaction provides in particular a starting point here (Gehring and Oberthür 2009; Oberthür and Gehring 2006, 2011; see also Ovodenko and Keohane 2012). In the following, we first introduce "social network analysis" to the study of institutional interaction and combine it with cognitive interaction (see Jinnah 2011: 3; Brosig 2011: 158; Selin and VanDeveer 2003). This approach has rarely been employed so far in the literature, which may come across surprising given the similarities in the treatment of interactions and the methodological potential network analysis offers.

Network analysis deals with actors' interactions by examining countries, institutions, or individuals that are connected through and can mutually depend on each other via ties or linkages. A network is defined by a finite set of nodes, i.e., actors, and by the links, i.e., relationships, that tie two or more actors to each other (Wasserman and Faust 1997; Borgatti et al. 2009; Hafner-Burton et al. 2009; Maoz 2010; Ward et al. 2011). Most network studies in international relations employ countries as nodes and analyze, for example, how ties through the network of memberships in intergovernmental organizations affect outcomes such as conflict, convergence in policy outcomes, or pollution control (e.g., Cao 2009; Cao and Prakash 2010; Dorussen and Ward 2008; Hafner-Burton et al. 2009). In contrast, and as specified below, our study focuses on international institutions as 
nodes, while the mutual membership of a country in those institutions can be considered a direct link between them (see also Gehring and Oberthür 2009: 139; Hofmann 2010: 103). More mutual members signify stronger ties that can transport resources such as information more efficiently between institutions. This treatment of institutional interaction mirrors cognitive interaction (Gehring and Oberthür 2009: 132f).

Regimes may share direct links, i.e., connections that link two institutions directly, and/or indirect links, i.e., ties to one or more than one intermediary that connect two international institutions. Direct and indirect links tie a regime to other regimes and determine the density, i.e., the cohesiveness of a network (Wasserman and Faust 1997: 314f). For the purpose of illustration, Fig. 1 shows a hypothetical network of five well-known international environmental institutions. The width of the edges is proportional to regimes' shared country memberships: more numerous ties are represented by denser links. This figure demonstrates that while most regimes have direct links, a few institutions have no or only weak direct connections with each other. For instance, the Convention on Biological Diversity in this hypothetical network is connected to the other regimes through much weaker links (if any) than, e.g., the UNFCCC. The former regime has also no direct link with, e.g., the convention on long-range transboundary air pollution (LRTAP), i.e., there is no single state that is a member in both organizations. The LRTAP, however, is connected to the UNFCCC, which, in turn, has a direct link to the Convention on Biological Diversity. Hence, the Convention on Biological Diversity and the LRTAP actually share an indirect link to one another via the UNFCCC as an intermediary. Network analysis offers the possibility to analyze direct flows of information as well as these longer chains involving (more than) one intermediary.

Against this background, we follow the logic of cognitive interaction (Gehring and Oberthür 2009: 132f) and argue that the resources that flow through ties pertain to information about and experiences with treaty design characteristics, which then influences other institutions. Consequently, direct and indirect links in networks facilitate the transmission of information (e.g., Ward 2006). The member states of two regimes then serve as vehicles that establish links between international institutions through the encounter of representatives in meetings and the working practices of these regimes. In other words, frequent encounters of states' diplomats facilitate the transmission of information about interests and intentions, and promote a common understanding thereof. Connections that are shorter and denser convey information with lower costs, more precisely, and faster (Dorussen and Ward 2008: 197). As argued then in the existent literature, this, ceteris paribus, leads to decreased uncertainty and, in our case, more knowledge about institutional design, its possibilities, and limitations (Pretty and Ward 2001: 209f; Hafner-Burton and Montgomery 2006; Dorussen and Ward 2008: 194f; Hafner-Burton et al. 2009: 569; Leifeld and Schneider 2012). Put differently, this interaction through network ties, "which comes into existence when individuals attempt to make best use of their individual resources" (Coleman 1990: 300), is likely to influence international institutions by "shaping common beliefs" (Hafner-Burton and Montgomery 2006: 8).

It thus seems plausible that information on institutional design should spread if two institutions are strongly linked to each other (Ward 2006: 151f; Dorussen and Ward 2008; Hafner-Burton et al. 2009; Leifeld and Schneider 2012). ${ }^{6}$ International institutions that are

\footnotetext{
${ }^{6}$ It is, of course, also possible that the kind of information on institutional design, which we focus on, spreads through different channels, such as government officials negotiating international agreements in different sectors, officials from international organizations, etc. However, this should not work against our proposed mechanism, since there is no reason to assume that contrary information should spread through these different channels.
} 


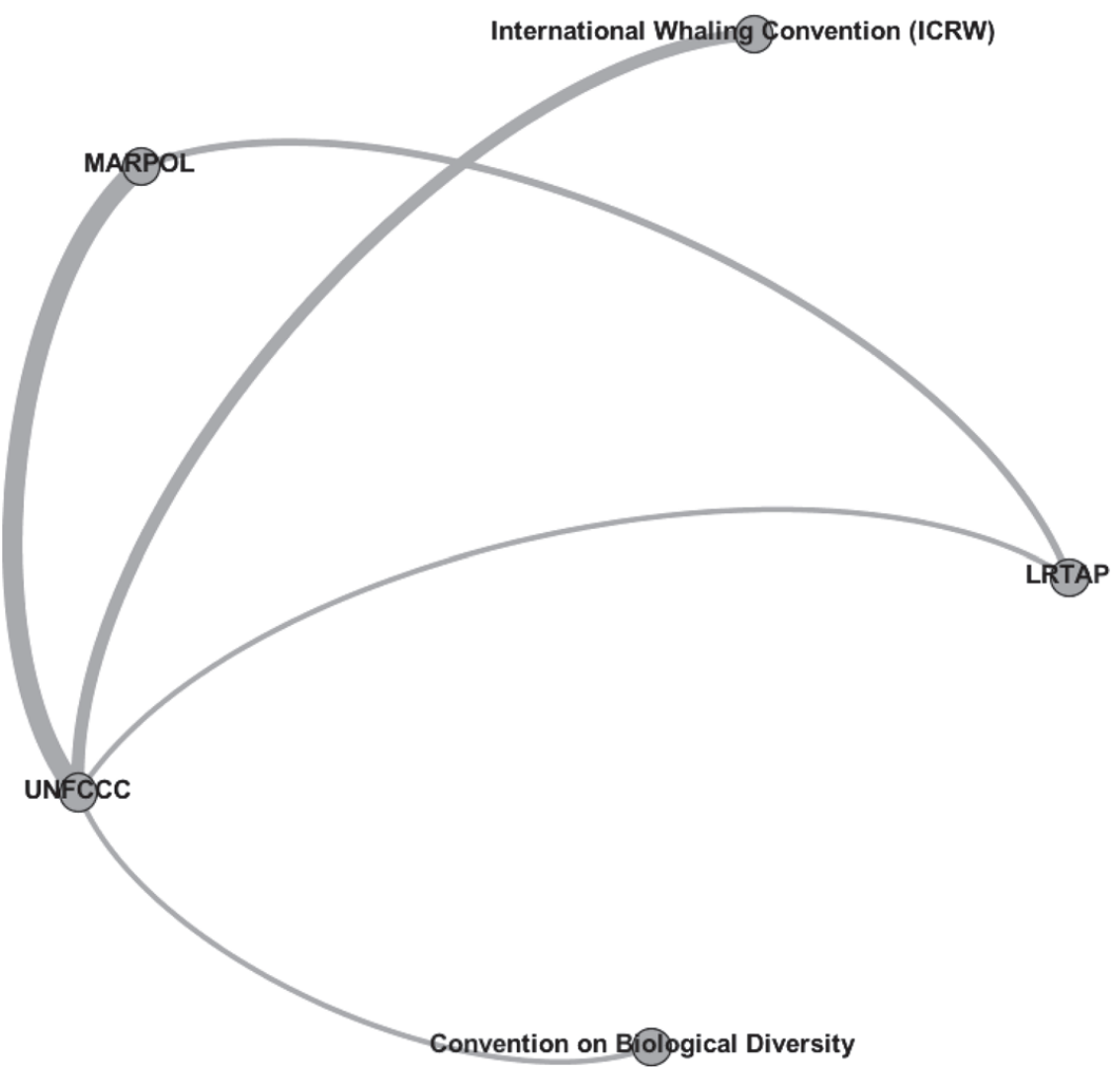

Fig. 1 A hypothetical, undirected network of international environmental institutions

more strongly connected will share more information (see Ward 2006: 151f; Haas 1993: 187, 1997: 200; Slikker and van den Nouweland 2001: 21ff; Dorussen and Ward 2008: 195). In contrast, if two institutions are not or only remotely linked to each other, information on institutional design does not transfer that easily. Based on this discussion, a first expectation might be that the higher the degree of connectedness between two institutions, the higher the likelihood that they are more similar in their institutional design.

\section{Soft law, hard law, and design similarity in the realm of institutional interaction}

However, we contend that this process does not only depend on the strength of connectedness between institutions, but also on the type of institutional design. In particular, we argue that regime interaction requires strong and multiple links between institutions, but only leads to institutional similarity in the case of soft law. On the other hand, institutional interaction is unlikely to induce design similarity in the case of hard law.

International institutions vary considerably in their design, which we operationalize by the degree of legalization (Abbott et al. 2000; see also Shaffer and Pollack 2010, 2011). Institutions can be highly legalized if they are characterized by clear obligations (i.e., an institution's rules can be enforced upon its members), are precise (i.e., rules are clearly and unambiguously defined), and delegate authority to a supranational body (i.e., a body like a secretariat that has authority to implement, interpret, and apply rules). Other regimes lack some or all of these features. Following Abbott et al. (2000), we use the term hard law for the first scenario and soft law when referring to institutions of the second category (see also Abbott and Snidal 2000; Skjærseth et al. 2006; see also Shaffer and Pollack 2010, 2011). 
Generally, hard-law treaties with demanding obligations are likely to require more ambitious modifications in states' behavior and strong enforcement mechanisms put further limits to their freedoms, since these mechanisms are designed for ensuring policy congruence with the obligations specified in an institutional treaty (Rosendorff and Milner 2001; Rosendorff 2005). Similarly, the delegation of authority makes it more difficult for states to interpret a respective agreement in a self-serving or biased manner. Thus, hardlaw regimes are more costly and less attractive to (potential) members (Slaughter 2004; Skjærseth et al. 2006). In other words, hard law is likely to constrain governmental autonomy or sovereignty, which we define as "the institutionalization of public authority within mutually exclusive jurisdictional domains" (Ruggie 1986: 143). However, since hard law is comprised of precisely stated obligations and as it delegates authority to implement and interpret these, it is likely to be more credible and can provoke states more effectively to reach the policy goals they agreed on. ${ }^{7}$ This suggests that hard law might be able to effectively solve a problem at hand, but it is unlikely to be attractive to many (potential) members of international institutions due to the outlined sovereignty costs in the first place.

On the other hand, soft-law treaties are more flexible and usually do not constrain states' sovereignty in such a severe manner as hard law does (Slaughter 2004; see also Fearon 1998; Rosendorff and Milner 2001; Koremenos et al. 2001; Rosendorff 2005). Hence, soft law is regularly seen as solution countries can easily agree on as it gives them the opportunity to adapt commitments to their particular needs, allowing regime members a range of discretion and flexibility in interpreting and implementing their commitments (Skjærseth et al. 2006: 115). In particular, flexibility makes it possible for states to respond to unanticipated shocks or special domestic circumstances without compromising existing institutional arrangements (Rosendorff and Milner 2001; Rosendorff 2005). Furthermore, when countries' preferences are deeply divergent, soft law can produce more opportunities for compromises (see also Skjærseth et al. 2006). A shortcoming of soft law, however, is that its rules are often vague, since no precise or quantifiable targets are set. This induces that these kinds of regimes may not solve the underlying problem effectively and are often viewed as "window dressing," because of the lack of credibility. In addition, the adaptability of soft law can also give states the opportunity to shirk, thus leading to reduced forms of actual cooperation.

It follows from these arguments that, while upholding the claim that experiences with and information on institutional design can flow between regimes that are well connected, there exists a tradeoff between soft and hard law (Downs et al. 1996; Bernauer et al. 2013; Spilker and Koubi 2012). This tradeoff essentially mirrors the rigidity-flexibility exchange in the institutional design literature (e.g., Fearon 1998; Rosendorff and Milner 2001; Koremenos et al. 2001; Rosendorff 2005). On the one hand, soft law may not necessarily be effective in solving an underlying problem. However, it should appear attractive to states due to its lower sovereignty costs. On the other hand, hard law is unlikely to be the most preferred option for states that value their autonomy and sovereignty in decision making, although it is potentially better suited to effectively address the problem an institution has been created for in the first place. In light of this rationale, when combining

\footnotetext{
7 This is because hard-law treaties reduce the risk of incomplete contracting by lowering the transaction costs of the law's application and by decreasing post-agreement costs such as management or enforcement (Rosendorff 2005). Furthermore, hard law may increase the reputational costs, a state will incur if it reneges on its commitments.
} 
it with institutional interaction and information flows in networks for explaining the degree of legalization of two institutions, we must elucidate what countries value most.

As emphasized, strong and various linkages between two regimes comprise information flows between these institutions, suggesting that states might learn from their experiences in the source regime and, thus, could be inclined to implement a similar design in a target treaty. Against this background, we might well claim that states' experience with the potential benefits of hard law in achieving effective problem solving is likely to travel to other regimes if a source and a target are well connected. In other words, since the flow of information is greater between regimes with similar membership, hard law might be transferred from the source to the target.

However, Young (1999) emphasizes that besides the perspective where a (source) regime and its network stimulate processes of reduced uncertainty and increased social capital, there exists another utilitarian way, where states operate according to a cost-benefit model: countries could find their experience with hard law not very appealing, since these treaties should on average impose costs on their sovereignty that are too high-and, in fact, higher than the benefits that might be derived from hard-law regimes. Global environmental governance typically involves issues that are unclear and consequences of potential actions that are uncertain (Ovodenko and Keohane 2012). States should therefore be more hesitant getting tied into agreements that pose higher costs, threats, or constraints to their national sovereignty. This argument is similar to Goldstein and Martin (2000: 620) who claim that the propensity of member states to commit to rules will decline with higher levels of hard law in the international trade regime: "if agreements are impossible to breach, either because of their level of obligation or because the transparency of rules increases the likelihood of enforcement, elected officials may find that the costs of signing such agreements outweigh the benefits." Consistently, Downs et al. (1996) argue that whether an agreement entails sovereignty costs ultimately depends on the depth of cooperation. As indicated above and as demonstrated in the research design below, this is a crucial part of our treatment of hard law. From an empirical lens, in addition, the observation that "[i]t is easier to reach agreement on substantively ambitious soft law than on hard law" (Skjærseth et al. 2006: 115) is also supported by, e.g., Bernauer et al. (2013) and Spilker and Koubi (2012). Both studies show that treaties with clear obligations are less attractive to members than treaties, which can be subsumed under the soft-law category. Finally, Abbott and Snidal (2000: 422) emphasize that "hard law restricts actors' behavior and even their sovereignty," while Biermann and Gupta (Biermann and Gupta 2011: 1,856 ) forcefully remind us that sovereignty is one of the most valuable goods for states. If it is one of the most valuable goods, however, the potential, yet uncertain benefits that could be derived from hard law are unlikely to outweigh the costs associated with sovereignty constraints.

In line with this literature, we claim that states have a stronger incentive to preserve their sovereignty, hence promoting the dissemination of soft law in the institutional setting. We hypothesize accordingly that soft law travels through strong linkages from one institution to another, thus leading to design similarity: countries' experience with soft law is likely to be more "satisfying" as it may partially (but perhaps not fully) solve the problem at hand, while it imposes fewer costs on states' sovereignty at the same time. Hence, the treaty characteristics that seem most attractive to governments are likely to pertain to soft law. Alternatively, two regimes are unlikely to be similar in their design if one of these institutions is characterized by hard law, i.e., states will have learned from their experience with hard law and may be more eager to implement soft law instead (see also Ovodenko and Keohane 2012: 523f). Accordingly, given that institutions do indeed share strong links 
with each other, we expect that institutional interaction will only lead to design similarity in the case of soft law:

$\mathbf{H}_{1}$ In the case of soft law, the higher the degree of connectedness between two institutions, the higher the likelihood that they are similar in their institutional design.

$\mathbf{H}_{2}$ In the case of hard law, the higher the degree of connectedness between two institutions, the lower the likelihood that they are similar in their institutional design.

\section{Research design}

\subsection{Data and dependent variables}

The foundation of our empirical analysis is a cross-sectional dataset compiled by Bernauer et al. (2013). After accounting for missing values for some covariates in these data, they are comprised of information on design features and treaty characteristics of 195 international environmental institutions. ${ }^{8}$ Most importantly, this dataset provides variables that match the concept of our dependent variable: international institutions' design and, specifically, their degree of legalization (Abbott et al. 2000).

Although our theoretical argument is likely to apply to any kind of institutional interaction, we have chosen global environmental agreements for the following reasons. First, Bernauer et al.'s (2013) dataset is the only source that offers comprehensive and reliable information for our theoretical concepts of interests. However, while these data cover all global international environmental regimes between 1952 and 2000, a potential shortcoming is their purely cross-sectional nature. This seems to be of minor importance, though. Bernauer et al. (2013) coded their data along the original institutional treaty documents, texts, charters, etc., which hardly change over time. Second, by restricting the analysis to one policy area, we are able to control for the impact of unit heterogeneity and, thus, can efficiently take care of remaining heterogeneity by means of a set of control variables. Third, our focus is on ties between regimes and how these affect institutional design. As indicated and as elaborated in detail below, we operationalize these ties via country memberships and, hence, require a sample of regimes that can, in principle, attract members from exactly the same population of countries in any given year. The agreements in our data are open to all countries in the international system and, therefore, meet this criterion.

The unit of analysis in the original data is a respective institution. The literature on institutional interaction, however, departs from this by focusing on a source and a target institution in order to isolate each interaction for a careful and thorough analysis in qualitative studies (Oberthür and Gehring 2006; Gehring and Oberthür 2009). Despite our quantitative setup, we follow this treatment by taking the directed dyad as the unit of analysis. Hence, our data entail one case for any possible dyadic combination of one regime with another. Note, moreover, since regime design features barely change over time, the possibility that we observe interaction between all those directed dyads in which the source institution has been established after the target institution is excluded ex ante.

\footnotetext{
${ }^{8}$ The online appendix provides a list of all considered regimes. Originally, Bernauer et al. (2013) relied on CIESIN (2006) and Mitchell (2008), and then deleted treaties from the data that, in their assessment, deal with environmental issues only at the margin or not at all. They also eliminated treaties that are not open for ratification to all countries globally.
} 
We thus drop these cases and only include those directed dyads in our data, in which the source institution has been established before or in the year the target institution has been founded. ${ }^{9}$ In order to control for any persistent underlying propensities of institutional dyads to implement soft or hard law, we cluster the standard errors on a respective dyad. The final sample consists of 17,980 observations.

In consistence with the theory, the dependent variable captures the degree of legalization similarity between two institutions in a dyad. To this end, we follow the suggested components of legalization in Abbott et al. (2000) who define legalization as a system of institutionalized rules, norms, and regulations that characterize regimes along three dimensions. First, there is obligation, i.e., an institution's degree of bondage and commitment. The rules of a regime may not necessarily be enforced in a legal sense, i.e., they may not be "subject to scrutiny under the general rules, procedures, and discourse of international law" (Abbott et al. 2000: 401; see also Porter and Welsh Brown 1996: 37). Based on this definition, we employ an item that measures whether the treaty itself establishes an enforcement mechanisms (1) or not (0). ${ }^{10}$ The rationale for using this measure is that only those institutions imply a real obligation to their members once their rules can be enforced. Importantly, an enforcement mechanism must be established within the context of a specific environmental treaty and not provided by a third party. An example for a treaty establishing an enforcement mechanism is the Kyoto Protocol's Subsidiary Body for Implementation that monitors and enforces the goals of this treaty.

Second, there is precision, i.e., the unambiguous definition of states' required actions in certain circumstances. High levels of precision unambiguously define the required actions of states in certain circumstances (Abbott et al. 2000: 401) and narrow the "scope for reasonable interpretation" (Abbott et al. 2000: 402), thereby introducing clarity into an institution's structure. This mechanism creates a non-contradictory framework of rules that can be carried out coherently. Our data include a dichotomous variable that scores the value of 1 if a treaty specifies quantitative targets or clear provisions. Similarly, this variable receives the value of 0 if an institutional treaty only contains ambiguous specifications of what has to be achieved. For example, a treaty could demand only that better air quality should be achieved instead of providing exact specifications for how much of emissions must be reduced.

Finally, legalization entails delegation, i.e., granting authority of implementation, interpretation, rule application, and dispute resolution to one or more third parties (Abbott et al. 2000: 401ff). In that way, states lose some degree of sovereign decision making, since bodies like secretariats take over power from states. We follow the recent literature on this (e.g., Jinnah 2010; Conliffe 2011; see also Abbott et al. 2000; Böhmelt and Pilster 2010) by using a variable on the existence of secretariats: an international institution has its own secretariat, it

\footnotetext{
9 The establishment of an institution refers to the first year this treaty is open for ratification. We also employed a more conservative setup by dropping those directed dyads in our data, in which the source institution has been established in the same year the target institution has been founded. The results based on this setup are identical to those reported below.

10 The variables we use to measure legalization are coded dichotomously. Arguably, certain treaty design variables may exhibit more than a binary variation. Bernauer et al. (2013) originally allowed for more finegrained categorizations for some of the variables. However, their coding process revealed the cure might be worse than the disease: since many of the treaties in the sample did not allow for a more fine-grained classification, Bernauer et al. (2013) ended up with only a few or no cases in several categories and, therefore, the coding became less reliable. Generally, this limitation mainly arises because the treaties are still rather heterogeneous, although they belong to the same policy area. In the end, Bernauer et al. (2013) decided that the empirical benefit from using more fine-grained scales is not worth the loss in data quality and reliability.
} 
uses an existing secretariat, or, in the case of protocols, it relies on the secretariat established by the framework convention (1); otherwise, this variable receives the value of 0 . Next to the references provided above that highlight the importance of secretariats as "active players" and acknowledge that states usually delegate some authority to secretariats (e.g., Jinnah 2010: 61; Conliffe 2011: 49), Shaffer (2001: 18) explains the role of secretariats most accurately: "on the basis of their expertise, impartial reputation, inside information, and close contacts with [...] diplomats, secretariat members can [...] help shape knowledge, frame issues, identify interests, facilitate coalition-building, and thereby affect outcomes" (see also Biermann and Bauer 2005; Biermann and Siebenhüner 2009). For example, the United Nations Convention to Combat Desertification secretariat's main task is to serve the Conference of the Parties and its subsidiary bodies, while it also oversees and supports national reporting on progress made to achieve the goals set by the convention.

Due to the dyadic nature of our data, we then combined these items into two different dependent variables that capture: (a) the degree of dyadic soft-law similarity and (b) the degree of dyadic hard-law similarity. To this end, in a first step, we created three new variables: the first of them receives the value of 1 if both institutions in a directed dyad have soft-law obligation ( 0 otherwise); the second of them receives the value of 1 if both institutions in a dyad have soft-law precision (0 otherwise); and the third of them receives the value of 1 if both institutions in a dyad have soft-law delegation ( 0 otherwise). In a second step, we created an additive variable, i.e., our final dependent variable concerning soft-law similarity is the sum of the three items from the first step and ranges in $[0 ; 3]$. This approach leads to a soft-law similarity measure for each specific dyad: while higher values signify a more similar degree of soft law between the source and the target institution, lower values represent weak or no soft-law similarities between two regimes. We then repeated this procedure for hard-law similarity between two regimes in a directed dyad. The only difference is that the three newly created items from the first step above receive a value of 1 in the case of hard-law similarity. The rationale behind this second dependent variable, which also ranges in [0;3], is the same as for the first one: ultimately, we obtain a dyadic measure of hard-law similarity. Higher values stand for dyadic design similarity in terms of hard law, while lower values pertain to dissimilarities in hard-law design features.

\subsection{Core explanatory variables: conceptualizing institutional ties via network measures}

We operationalize the ties between institutions and, hence, institutional interaction via regimes' co-members. For reasons of consistence with the outlined source-target approach, all of the following network measures are based on states' regime memberships in the year the target institution has been created. By membership, we refer to those countries that have ratified both agreements. ${ }^{11}$ We thus calculated every network variable for every year between 1952 and 2000 separately, and merged these items afterward into our data.

One objection to relying on all regime co-members between a source and a target institution could be that not all countries at the negotiating table have an equal say and are thus not equally important when it comes to designing a regime. At first glance, it might therefore be practical to treat only powerful member countries as the relevant network. However, we refrain from doing so due to two reasons. First, from an empirical point of

\footnotetext{
11 Instead of relying on all countries that have ratified both regimes, one could use only those members that were part of the negotiating group to each treaty. While this could be sensible from a theoretical perspective, we would lose about 50 treaties in our sample, for which we are lacking the corresponding data, thereby making our empirical approach less generalizable.
} 
view, it is almost impossible to decide a priori for every treaty, which countries should be those that are "relevant enough" to be included in these kinds of networks. Second, and more importantly, our argument on how information on design characteristics travels through the network between regimes applies to all member states universally. Hence, information should flow in a similar way regardless of whether we consider more or less powerful countries and, thus, the influence does not depend on the types of joint members we analyze. Consequently, we consider the network consisting of all member countries as both the empirically and theoretically relevant one.

Moreover, note that we neglect the influence of the environmental treaties in our data. Environmental regimes are usually weak, normative orders voluntarily agreed upon by their parties, and with low capacity for sanctions in the case of countries infringing the rules (Mayer et al. 1993: 393). Hence, environmental regimes generally lack the willingness (if they have organizations attached to them) and opportunity to play active, independent roles, making the specific purpose and institutionalization of organizations less important. This does not imply, however, that these treaties do not matter when assessing the effect of the network variables on design similarity. International environmental institutions establish the links between its member states in the first place through the encounter of representatives in meetings and the working practices of these institutions. Hence, these treaties matter primarily through their network effects, but since the power of most regimes is derived from their member states (Boehmer et al. 2004; Dorussen and Ward 2008: 190), we can thus in practice neglect environmental institutions' influence as an intervening variable (see King et al. 1994: 173).

We use three different variables that capture both direct and indirect connections between international environmental institutions. The first variable measuring the number of co-members equals the value of the edge in the graph that directly connects two regimes. We call this item Direct Links, which, for example, would receive a value of 6 for the directed dyad of the Montreal Protocol (established 1988; source institution) and the UNFCCC (established 1992; target institution), because these institutions have six member states in common in the year the UNFCCC has been established. The rationale behind this item stems from the fact that regimes might exchange and obtain information, and, consequently, be influenced by links that connect them via the shortest and most efficient ties, since these transmit information with lower costs, more precisely, and faster than longer or less efficient ties (Dorussen and Ward 2008: 197).

Second, we employ the Maximum Flow of Information, a variable that considers a regime's whole range and any strength of all ties to the entire network (Dorussen and Ward 2008; Ford and Fulkerson 1956; Freeman et al. 1991). In contrast to Direct Links, which only relies on those ties between two regimes in a dyad, the Maximum Flow of Information considers the entire network of a specific year to measure how an institution is linked to all other nodes in the network. More precisely, Maximum Flow of Information is calculated by,

$$
\text { Maximum Flow of Information }(i)=\sum_{\forall i=j} v(i, j)
$$

where $i$ is one of the two institutions in a directed dyad, $j$ pertains to any other regime in the whole network of a specific year, and $v$ stands for the value, i.e., the strength, of a tie linking the two regimes as measured by institutions' mutual state members (Dorussen and Ward 2008: 196). ${ }^{12}$ This variable essentially counts flows of information through all

\footnotetext{
12 In order to calculate Maximum Flow of Information with this equation, the network must satisfy the condition $r \leq(n-2)^{1 / 2}$, where $n$ is the number of institutions and $r$ is the ratio of the largest edge value in a network to the smallest edge value. This is given in our setup.
} 
possible chains of intermediaries, i.e., the existent number of direct and indirect links a regime has to all other regimes in the entire system (Ford and Fulkerson 1956). The higher the value of this monadic measure, the more possibilities for a regime to obtain and share information via direct and indirect linkages do exist. For introducing the Maximum Flow of Information into our dyadic setup, we calculate the "weakest link" in a dyad, i.e., the ties of the institution least embedded in a dyad govern this variable (Dorussen and Ward 2008: 197).

As a final core explanatory variable, we employ what is known as Simmelian ties in network analysis. A Simmelian tie is a reciprocally connected pair with mutual ties to third parties (Simmel 1950; Krackhardt 1999: 186). For example, the UNFCCC and the International Convention for the Prevention of Pollution from Ships (MARPOL) in Fig. 1 are reciprocally tied to each other; at the same time, however, both of them are also tied to the LRTAP. Accordingly, our third network measure counts the number of Simmelian ties between each pair of regimes. The logic behind this variable differs from the previous two items in the following ways. First, indirect connections between two regimes via an intermediary are taken into account. Our first network variable, Direct Links, only counts the direct connections between two international institutions.

Second, with regard to the indirect connections of two regimes, the Simmelian tie variable only takes into account the shortest paths via one intermediary. Information transmissions via the Maximum Flow of Information can be misperceived and exerted influences are likely to be weak, as the Maximum Flow of Information counts flows of information and influence through long chains of intermediaries. Hence, the most empirically plausible paths in "given the possibility of such distortion are short ones" (Dorussen and Ward 2008: 197) and the Simmelian tie variable is a more nuanced measure than the Maximum Flow of Information.

\subsection{Control variables: underlying problem structure and public goods}

We also consider a set of control covariates that may influence the degree of institutional similarity between two treaties. The first cluster of control variables is based on the literature on the effectiveness of international environmental regimes, which highlights the importance of an institution's underlying problem structure (e.g., Young 1999; Mitchell 2006). Miles et al. (2002; see also Böhmelt and Pilster 2010: 247), for instance, use incongruity, asymmetry, and the cumulative cleavage structure to determine the level of "malignancy," which they combine with "uncertainty" in order to operationalize environmental problems. The authors also argue that the underlying problem of an environmental regime influences its institutional design: depending on the problem an institution has been created for, there are likely to be different degrees of issue scope, centralization, or flexibility (Koremenos et al. 2001; Mitchell 2006). While Bernauer et al.'s (2013) data do not include variables that measure, e.g., the level of malignancy or uncertainty of a regime's problem structure directly, they contain information on the respective issue or problem an institution deals with. More specifically, we include dummy variables for either regime in a dyad that indicate whether a regime deals with (a) matters of environmental pollution (Pollution 1 for whether the source institution in a dyad regulates a pollution issue or not; Pollution 2 for whether the target institution in a dyad regulates a pollution issue or not); (b) the protection of endangered species, microorganisms, and wildlife (Species 1 and Species 2); (c) nuclear energy issues within the environmental sphere (Nuclear 1 and Nuclear 2); and (d) particular ecosystems such as desertification, barren land, or wetlands (Habitat 1 and Habitat 2). We use these variables as proxies for the 
different problem structures regimes may have, since Miles et al. (2002) show that an institution's underlying problem structure does indeed vary over issues.

With regard to the second cluster of control variables, we take into account the logic that actors may find it difficult to organize themselves and, ultimately, are able to agree on an "optimal design" for dealing with an environmental problem if they face a global public good (Chamberlain 1974; Olson 1965; Snidal 1996). Hence, it seems plausible that this affects the degree of legalization of regimes and, as a result, their design similarity. We consider two variables that identify whether a global public good characterizes either regime in a dyad or not (Global Public Good 1 and Global Public Good 2), and we further include variables in order to make the distinction between global and domestic public goods (Domestic Public Good 1 and Domestic Public Good 2). ${ }^{13}$

\section{Empirical findings}

In Table 1, we employ Soft-Law Similarity as the dependent variable and run ordered probit models due to the ordinal scale of this item. Each model in this table uses a different network measure, thus allowing us to directly examine which factor exerts what kind of influence. Moreover, despite their different operationalizations, all network variables essentially seek to capture information flows between regimes. We, thus, can demonstrate that our results are robust. Table 2 follows this logic, but we substitute Soft-Law Similarity for Hard-Law Similarity. Finally, since coefficients in nonlinear models cannot be interpreted as slopes or elasticities, we calculated substantive quantities of interest for Figs. 2 and 3. Here, we show first-difference estimates for the values of our respective dependent variable as one network variable changes values from its minimum to its maximum, while all others items are held constant at their medians.

We start with the examination of the results for Soft-Law Similarity. Evidently, we obtain support for our first hypothesis. As argued, the more ties between two regimes, either directly or indirectly, the more likely that these two institutions are characterized by design similarity in the form of soft-law similarity. This view is supported by the positive coefficients of Direct Links, Maximum Flow of Information, and Simmelian Ties in Table 1 and the corresponding first differences in Fig. 2. For example, when moving from the minimum toward the maximum of Direct Ties, the predicted probability to see full similarity in two regimes' soft law (Soft-Law Similarity $=3$ ) increases by more than $40 \%$. On the contrary, the less connected two regimes in the network of international environmental institutions, the less likely it is that soft law characterizes both mutually. Ultimately, we conclude that our argument presented in the first hypothesis holds true: a closer connection between two international institutions, either via direct or indirect links, induces a stronger degree of soft-law similarity. Hence, although we explicitly do not want to exclude the possibility that soft law may also be effective in addressing environmental problems, that states learn from this, and then transfer their insights into the design of a target institution, it seems more plausible from our argumentation and the results here that regimes are similar in their soft-law design due to states' concerns about sovereignty and autonomy. Soft law hardly poses any challenges to states' power, and once this lesson has been learned in a source institution, it is more likely that this design is transferred to a target institution if these two regimes are well connected to each other.

13 The baseline category we leave out of the models pertains to those treaties that regulate mixed public goods, i.e., issues that have some regional or domestic component, but also a transnational character. 
Table 1 Institutional interaction from a network perspective: Soft-Law Similarity, 1952-2000

\begin{tabular}{|c|c|c|c|}
\hline & Model 1 & Model 2 & Model 3 \\
\hline Direct links & $\begin{array}{l}0.07 * * * \\
(0.01)\end{array}$ & & \\
\hline Maximum flow of information & & $\begin{array}{l}0.01 * * * \\
(0.00)\end{array}$ & \\
\hline Simmelian ties & & & $\begin{array}{l}0.01 * * * \\
(0.00)\end{array}$ \\
\hline Global Public Good 1 & $\begin{array}{l}0.29 * * * \\
(0.03)\end{array}$ & $\begin{array}{l}0.31 * * * \\
(0.03)\end{array}$ & $\begin{array}{l}0.30 * * * \\
(0.03)\end{array}$ \\
\hline Global Public Good 2 & $\begin{array}{l}-.06^{*} \\
(0.03)\end{array}$ & $\begin{array}{l}-0.07 * * \\
(0.03)\end{array}$ & $\begin{array}{l}-0.08 * * \\
(0.03)\end{array}$ \\
\hline Domestic Public Good 1 & $\begin{array}{l}0.05 \\
(0.04)\end{array}$ & $\begin{array}{l}0.07 * * \\
(0.04)\end{array}$ & $\begin{array}{l}0.05 \\
(0.04)\end{array}$ \\
\hline Domestic Public Good 2 & $\begin{array}{l}-0.54 * * * \\
(0.04)\end{array}$ & $\begin{array}{l}-0.56 * * * \\
(0.04)\end{array}$ & $\begin{array}{l}-0.56 * * * \\
(0.04)\end{array}$ \\
\hline Pollution 1 & $\begin{array}{l}-0.05^{* * * *} \\
(0.02)\end{array}$ & $\begin{array}{l}-0.06 * * * \\
(0.02)\end{array}$ & $\begin{array}{l}-0.05^{* *} \\
(0.02)\end{array}$ \\
\hline Pollution 2 & $\begin{array}{l}-0.49 * * * \\
(0.02)\end{array}$ & $\begin{array}{l}-0.49 * * * \\
(0.02)\end{array}$ & $\begin{array}{l}-0.49 * * * \\
(0.02)\end{array}$ \\
\hline Species 1 & $\begin{array}{l}0.17 * * * \\
(0.02)\end{array}$ & $\begin{array}{l}0.17 * * * \\
(0.02)\end{array}$ & $\begin{array}{l}0.17 * * * \\
(0.02)\end{array}$ \\
\hline Species 2 & $\begin{array}{l}-0.19 * * * \\
(0.02)\end{array}$ & $\begin{array}{l}-0.20 * * * \\
(0.02)\end{array}$ & $\begin{array}{l}-0.21 * * * \\
(0.02)\end{array}$ \\
\hline Nuclear 1 & $\begin{array}{l}0.12 * * * \\
(0.03)\end{array}$ & $\begin{array}{l}0.14 * * * \\
(0.03)\end{array}$ & $\begin{array}{l}0.12 * * * \\
(0.03)\end{array}$ \\
\hline Nuclear 2 & $\begin{array}{l}0.10 * * * \\
(0.03)\end{array}$ & $\begin{array}{l}0.11 * * * \\
(0.03)\end{array}$ & $\begin{array}{l}0.10 * * * \\
(0.03)\end{array}$ \\
\hline Habitat 1 & $\begin{array}{l}0.05 * * \\
(0.02)\end{array}$ & $\begin{array}{l}0.05 * * \\
(0.02)\end{array}$ & $\begin{array}{l}0.06 * * \\
(0.02)\end{array}$ \\
\hline Habitat 2 & $\begin{array}{l}-0.05^{* *} \\
(0.02)\end{array}$ & $\begin{array}{l}-0.05^{* * *} \\
(0.02)\end{array}$ & $\begin{array}{l}-0.05^{* *} \\
(0.02)\end{array}$ \\
\hline$N$ & 17,980 & 17,980 & 17,980 \\
\hline Log pseudo likelihood & $-17,160.10$ & $-17,199.00$ & $-17,129.70$ \\
\hline$\chi^{2}$ & $1,155.40 * * *$ & $1,130.40 * * *$ & $1,297.30 * * *$ \\
\hline AIC & $34,352.10$ & $34,430.00$ & $34,291.40$ \\
\hline
\end{tabular}

Cut points not reported. Clustered robust standard errors in parentheses

$* p<0.10 ; * * p<0.05 * * * p<0.01$ (two-tailed)

Coming to our analyses for Hard-Law Similarity, as proposed in the second hypothesis, we observe a somewhat opposite effect of any network measure as in the case of Soft-Law Similarity. More specifically, Table 2 and Fig. 3 demonstrate that Direct Links, Maximum Flow of Information, and Simmelian Ties have negative coefficients and negative or closeto-zero first differences for higher values of Hard-Law Similarity. In fact, the less connected two regimes are in the network of international environmental institutions, the more likely it is that hard law characterizes both. While this goes against the general expectation that design similarity is induced through closer regime ties universally, it is in consistence with our rationale that led to the second hypothesis: countries may find their experience with hard-law treaties not alluring, since these treaties impose higher costs on their 
Table 2 Institutional interaction from a network perspective: Hard-Law Similarity, 1952-2000

\begin{tabular}{|c|c|c|c|}
\hline & Model 4 & Model 5 & Model 6 \\
\hline Direct links & $\begin{array}{l}-0.09 * * * \\
(0.01)\end{array}$ & & \\
\hline Maximum flow of information & & $\begin{array}{l}-0.01 * * * \\
(0.00)\end{array}$ & \\
\hline Simmelian ties & & & $\begin{array}{l}-0.01^{* * *} \\
(0.00)\end{array}$ \\
\hline Global Public Good 1 & $\begin{array}{l}-0.22 * * * \\
(0.03)\end{array}$ & $\begin{array}{l}-0.23 * * * \\
(0.03)\end{array}$ & $\begin{array}{l}-0.22 * * * \\
(0.03)\end{array}$ \\
\hline Global Public Good 2 & $\begin{array}{l}-0.06^{* * *} \\
(0.03)\end{array}$ & $\begin{array}{l}-0.06^{* *} \\
(0.03)\end{array}$ & $\begin{array}{l}-0.04 \\
(0.03)\end{array}$ \\
\hline Domestic Public Good 1 & $\begin{array}{l}0.02 \\
(0.03)\end{array}$ & $\begin{array}{l}-0.02 \\
(0.03)\end{array}$ & $\begin{array}{l}0.01 \\
(0.03)\end{array}$ \\
\hline Domestic Public Good 2 & $\begin{array}{l}0.37 * * * \\
(0.03)\end{array}$ & $\begin{array}{l}0.37 * * * \\
(0.03)\end{array}$ & $\begin{array}{l}0.39 * * * \\
(0.03)\end{array}$ \\
\hline Pollution 1 & $\begin{array}{l}0.07 * * * \\
(0.02)\end{array}$ & $\begin{array}{l}0.08 * * * \\
(0.02)\end{array}$ & $\begin{array}{l}0.08 * * * \\
(0.02)\end{array}$ \\
\hline Pollution 2 & $\begin{array}{l}0.23 * * * \\
(0.02)\end{array}$ & $\begin{array}{l}0.24 * * * \\
(0.02)\end{array}$ & $\begin{array}{l}0.24 * * * \\
(0.02)\end{array}$ \\
\hline Species 1 & $\begin{array}{l}-0.18 * * * \\
(0.02)\end{array}$ & $\begin{array}{l}-0.17 * * * \\
(0.02)\end{array}$ & $\begin{array}{l}-0.18 * * * \\
(0.02)\end{array}$ \\
\hline Species 2 & $\begin{array}{l}0.05 * * \\
(0.02)\end{array}$ & $\begin{array}{l}0.07 * * * \\
(0.02)\end{array}$ & $\begin{array}{l}0.06 * * * \\
(0.02)\end{array}$ \\
\hline Nuclear 1 & $\begin{array}{l}-0.50 * * * \\
(0.03)\end{array}$ & $\begin{array}{l}-0.52 * * * \\
(0.03)\end{array}$ & $\begin{array}{l}-0.51 * * * \\
(0.03)\end{array}$ \\
\hline Nuclear 2 & $\begin{array}{l}-0.28 * * * \\
(0.03)\end{array}$ & $\begin{array}{l}-0.28 * * * \\
(0.03)\end{array}$ & $\begin{array}{l}-0.28 * * * \\
(0.03)\end{array}$ \\
\hline Habitat 1 & $\begin{array}{l}-0.11 * * * \\
(0.02)\end{array}$ & $\begin{array}{l}-0.10^{* * *} \\
(0.02)\end{array}$ & $\begin{array}{l}-0.12^{* * * *} \\
(0.02)\end{array}$ \\
\hline Habitat 2 & $\begin{array}{l}-0.01 \\
(0.02)\end{array}$ & $\begin{array}{l}-0.01 \\
(0.02)\end{array}$ & $\begin{array}{l}-0.01 \\
(0.02)\end{array}$ \\
\hline$N$ & 17,980 & 17,980 & 17,980 \\
\hline Log pseudo likelihood & $-21,675.20$ & $-21,797.80$ & $-21,672.80$ \\
\hline$\chi^{2}$ & $1,187.10 * * *$ & $1,079.20 * * *$ & $1,347.30 * * *$ \\
\hline AIC & $43,382.40$ & $43,627.60$ & $43,377.50$ \\
\hline
\end{tabular}

Cut points not reported. Clustered robust standard errors in parentheses

$* p<0.10 ; * * p<0.05 * * * p<0.01$ (two-tailed)

sovereignty. Ultimately, we observe that the implementation of hard law in the source regime is then prevented in the target regime. For example, the first-difference estimate for Hard-Law Similarity $=2$ scores, a negative and statistically significant value of 0.25.

Furthermore, according to Figs. 2 and 3, we observe that the network measures incorporating indirect links exert on average a lower effect than Direct Ties, which operationalizes only direct linkages. While this means that indirect links also transmit and convey information flows between regimes, they can only be considered as imperfect substitutes for direct ties if these do not exist or may be inactive (Dorussen and Ward 2008). Hence, direct linkages between institutions are the most efficient and effective ones. 


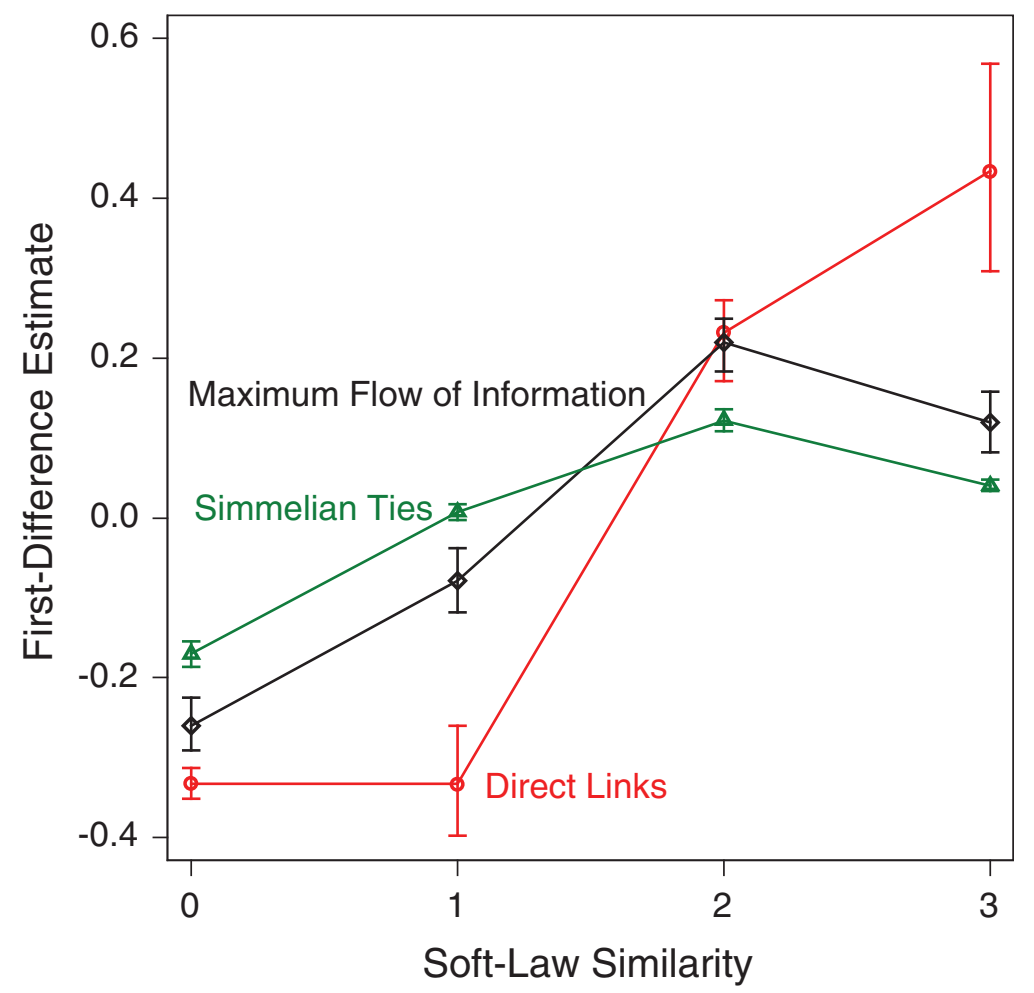

Fig. 2 First-difference estimates: Soft-Law Similarity. Ninety percent confidence intervals denoted by vertical bars

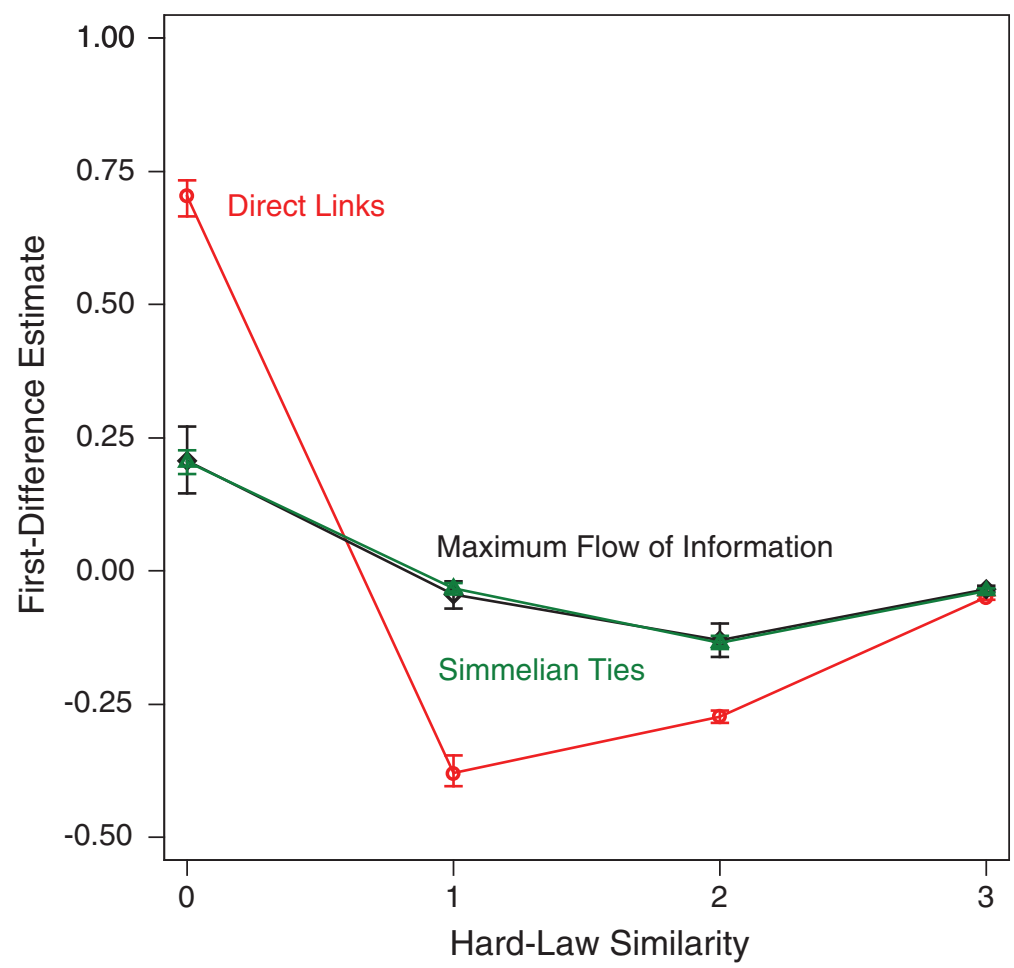

Fig. 3 First-difference estimates: Hard-Law Similarity. Ninety percent confidence intervals denoted by vertical bars

With regard to the control variables, it seems that these do a fairly good job in capturing influences from problem structure and good type. For example, Table 2 shows that the public-good problematic at the global level makes it generally less likely that two institutions in a dyad are similar in their hard-law design. However, the item Domestic Public 
Good 2 displays a positive and highly significant coefficient, i.e., two institutions are more likely to have hard-law similarity if the target regime in a dyad deals with a domestic public good. In consistence with the variables concerning regimes' problem structure, it thus depends on the source/target regime's characteristics and, ultimately, remains an empirical question how these covariates influence hard- or soft-law design. That being said, the signs of the coefficients generally change over Tables 1 and 2-which is expected given that the two different dependent variables in those tables rely on opposing theoretical considerations and empirical operationalizations.

Finally, we also conducted a series of robustness checks with respect to both the statistical procedure used and the variables included in the model. These additional tests, which we thoroughly discuss in the online appendix, show that our core conclusions hold.

\section{Conclusion}

Do institutional design characteristics flow through the network of international regimes, thus supporting the idea of institutional interaction? Our research suggests that this is indeed the case, yet only for a specific set of design characteristics. Generally, our findings based on the network analysis of 195 international environmental treaties between 1952 and 2000 support the argument that institutional interplay affects the design of international institutions if these are connected with each other. However, interaction only leads to a higher degree of design similarity in the case of soft law.

The theoretical rationale behind our results is that more connections between institutions facilitate the transmission of information and, hence, should make it more likely that their design is similar. States learn from their experience with regime designs and, since stronger ties induce common norms and behavior, they might be inclined to adapt the same treaty characteristics that were used in an earlier regime under those circumstances. However, we also argued that ties or connections might not necessarily transfer information about the effectiveness or efficiency of hard law in one regime to another, but rather states' concerns about sovereignty and autonomy. Since hard law imposes more sovereignty costs on (potential) member countries, we ultimately observe a negative effect of our network measures on institutional design similarity here.

In addition to filling an important gap in the scholarly literature on institutional interplay, our research may also highlight some policy implications (see also Oberthür and Gehring 2011: 48f). For example, policymakers might assume that if states eventually agreed on hard law for the design of one regime, they might be more willing to implement it in another institution as well. This would induce that hard law could gradually flow through the entire network of institutions (Skjærseth et al. 2006), which might be desirable as hard law is generally seen as more effective than soft law (see Abbott et al. 2000; see also Shaffer and Pollack 2010, 2011). Unfortunately, however, but in line with earlier research on this topic (Goldstein and Martin 2000; Bernauer et al. 2013; Spilker and Koubi 2012), our results can hardly be taken as evidence for this. Obviously, neither do we want to recommend breaking up the existing ties between institutions nor not establishing new linkages at all against this background-particularly since the existing research on institutional interaction frequently points to synergetic effects in the case of regimes' performance. We do suggest, nevertheless, that policymakers should engage more strongly in managing institutional interaction (Oberthür 2009) and pay close attention to these ties when creating or re-designing institutions: linkages between institutions not only transfer information from one regime to another, but can also signal a lot about the underlying preferences of states. If taking into 
account this interaction between institutions, we gain a substantial amount of information $e x$ ante about those actors that eventually make the decisions.

In light of this discussion, we hope that our work contributes to the existing literature in important ways. Needless to say that many questions remain unanswered and various avenues for further research exist (see also Oberthür and Gehring 2011: 51f). We outline four of them. First, while our theoretical argument is of general nature, the empirical test refers to the realm of environmental politics. Future research might, therefore, want to examine whether our findings also hold for other issue areas such as trade or human rights. Due to the limited availability of data, this points to new data collection efforts.

Second, we focused on regimes' design similarities, while the previous literature primarily studied how institutional interplay influences regimes' performance. Our research design could be well applied to this case of effectiveness, although one would require a valid and reliable performance measure first, which can be used for a wide array of international institutions across issue areas (Miles et al. 2002). In principle, though, we see a lot of potential in using network analysis for future research, especially due to the higher degree of generalizability resulting from those approaches.

Third, we operationalized the network of international institutions via states' membership ties. However, other actors might be involved in the process of information sharing, influence, and, hence, cognitive interaction. For instance, international bureaucrats working in pre-existing international institutions often are involved in design negotiations (Johnson 2013a, b). Non-state actors or epistemic communities might be equally important in transferring information from one institution to another. Hence, institutional interaction is not solely state-based, however, we had to exclude the alternative networks based on those other actors due to the lack of data. Based on new data collection efforts, future work might therefore want to address this issue more thoroughly than we could possibly do here.

Finally, our theoretical argument has been built on the notion that states value their sovereignty more than gains in effectiveness from hard law. In fact, this claim is in consistence with the empirical observation that only a minority of institutions can actually be characterized as hard law (Porter and Welsh Brown 1996; Abbott et al. 2000; Abbott and Snidal 2000; see also Shaffer and Pollack 2010, 2011). However, some institutions do rely on obligatory norms, precise regulations, and delegation and the crucial question here is why states were actually able to agree on such an institutional setup in the first place if it does constrain their autonomy? An ad hoc explanation (although we tried to control for this) could be that some states particularly suffer from a specific (environmental) problem and, thus, are likely to value hard law more because of its potentially higher effectiveness. This rationale is supported, e.g., in case of the mercury convention (Andresen et al. 2013). While attempting to provide a thorough answer on this goes beyond the scope of this paper, a systematic study in this regard could substantially further our understanding of the mechanisms persistent in global governance and within the networks of international institutions.

Acknowledgments We thank Manfred Elsig, Tana Johnson, Xavier Fernández-i-Marín, the participants of the 6th Annual Conference on the Political Economy of International Organizations (PEIO), the participants of the Workshop on the Design and Effects of International Institutions at the ECPR Joint Sessions 2013, and the journal's anonymous reviewers as well as the editor for helpful comments and advice. The replication materials for the data analysis can be obtained from the authors on request.

\section{References}

Abbott, K., Keohane, R., Moravcsik, A., Slaughter, A.-M., \& Snidal, D. (2000). The concept of legalization. International Organization, 54(3), 401-419. 
Abbott, K., \& Snidal, D. (2000). Hard and soft law in international governance. International Organization, 54(3), 421-456.

Andresen, S., Rosendal, K., \& Skjærseth, J. B. (2013). Why negotiate a legally binding mercury convention? International Environmental Agreements, 13(4), 425-440.

Bernauer, T., Kalbhenn, A., Koubi, V., \& Spilker, G. (2013). Is there a "depth versus participation" dilemma in international cooperation? Review of International Organizations, 8(4), 477-497.

Biermann, F., \& Bauer, S. (2005). Managers of global governance: Assessing and explaining the influence of international bureaucracies. Working paper No. 15: The global governance project.

Biermann, F., \& Gupta, A. (2011). Accountability and legitimacy in earth system governance: A research framework. Ecological Economics, 70(11), 1856-1864.

Biermann, F., \& Siebenhüner, B. (Eds.). (2009). Managers of global change: The influence of environmental bureaucracies. Cambridge, MA: MIT Press.

Boehmer, C., Gartzke, E., \& Nordstrom, T. (2004). Do intergovernmental organizations promote peace? World Politics, 5(7), 1-38.

Böhmelt, T., \& Pilster, U. (2010). International environmental regimes-legalisation, flexibility and effectiveness. Australian Journal of Political Science, 45(2), 245-260.

Borgatti, S., Mehra, A., Brass, D., \& Labianca, G. (2009). Network analysis in the social sciences. Science, 323(5916), 892-895.

Brosig, M. (2011). Overlap and interplay between international organizations: Theories and approaches. South African Journal of International Affairs, 18(2), 147-167.

Cao, X. (2009). Networks of intergovernmental organizations and convergence in domestic economic policies. International Studies Quarterly, 53(4), 1095-1130.

Cao, X., \& Prakash, A. (2010). Trade competition and domestic pollution: A panel study, 1980-2003. International Organization, 64(3), 481-503.

Chamberlain, J. (1974). Provision of collective goods as a function of group size. American Political Science Review, 68(2), 707-716.

CIESIN. (2006). Environmental treaties and resource indicators (ENTRI). http://sedac.ciesin.columbia.edu/ entri/, Accessed Oct 31, 2013.

Coleman, J. (1990). Foundations of social theory. Cambridge, MA: Harvard University Press.

Conliffe, A. (2011). Combating ineffectiveness: Climate change bandwagoning and the UN convention to combat desertification. Global Environmental Politics, 11(3), 44-63.

Dorussen, H., \& Ward, H. (2008). Intergovernmental organizations and the Kantian peace-a network perspective. Journal of Conflict Resolution, 52(2), 189-212.

Downs, G., Rocke, D. M., \& Barsoom, P. (1996). Is the good news about compliance good news for cooperation? International Organization, 52(3), 379-406.

Fearon, J. D. (1998). Bargaining, enforcement, and international cooperation. International Organization, 52(2), 269-305.

Ford, L. R., \& Fulkerson, D. R. (1956). Maximal flow through a network. Canadian Journal of Mathematics, 8(5), 399-404.

Freeman, L., Borgatti, S., \& White, D. R. (1991). Centrality in valued graphs: A measure of betweenness based on network flow. Social Networks, 13(2), 141-154.

Gehring, T., \& Oberthür, S. (2009). The causal mechanism of interaction between international institutions. European Journal of International Relations, 15(1), 125-156.

Goldstein, J., \& Martin, L. (2000). Legalization, trade liberalization and domestic politics: A cautionary note. International Organization, 54(3), 603-632.

Grilo, C. (2011). Institutional interplay in networks of marine protected areas with community-based management. Coastal Management, 39(4), 440-458.

Haas, P. M. (1993). Epistemic communities and the dynamics of international environmental cooperation. In V. Rittberger (Ed.), Regime theory and international relations (pp. 168-201). Oxford: Oxford University Press.

Haas, P. M. (1997). Scientific communities and multiple paths to environmental management. In L. A. Brooks \& S. D. VanDeVeer (Eds.), Saving the seas: Values, scientists, and international governance (pp. 193-228). College Park, MD: Maryland Sea Grant College.

Hafner-Burton, E., Kahler, M., \& Montgomery, A. (2009). Network analysis for international relations. International Organization, 63(3), 559-592.

Hafner-Burton, E., \& Montgomery, A. (2006). Power positions-international organizations, social networks, and conflict. Journal of Conflict Resolution, 50(1), 3-27.

Hofmann, S. (2010). Why institutional overlap matters: CSDP in the European security architecture. Journal of Common Market Studies, 49(1), 101-120.

Jinnah, S. (2010). Overlap management in the world trade organization: Secretariat influence on tradeenvironment politics. Global Environmental Politics, 10(2), 54-79. 
Jinnah, S. (2011). Climate change bandwagoning: The impacts of strategic linkages on regime design, maintenance, and death. Global Environmental Politics, 11(3), 1-9.

Johnson, T. (2013a). Institutional design and bureaucrats' impact on political control. Journal of Politics, 75(1), 183-197.

Johnson, T. (2013b). Looking beyond states: Openings for international bureaucrats to enter the institutional design process. Review of International Organizations, 8(4), 499-519.

King, G., Keohane, R., \& Verba, S. (1994). Designing social inquiry: Scientific inference in qualitative research. Princeton, NJ: Princeton University Press.

Koremenos, B., Lipson, C., \& Snidal, D. (2001). The rational design of international institutions. International Organization, 55(4), 761-799.

Krackhardt, D. (1999). The ties that torture: Simmelian tie analysis in organizations. Research in the Sociology of Organizations, 16(1), 183-210.

Leifeld, P., \& Schneider, V. (2012). Information exchange in policy networks. American Journal of Political Science, 56(3), 731-744.

Maoz, Z. (2010). Networks of nations: The evolution, structure, and impact of international networks, 1816-2001. Cambridge: Cambridge University Press.

Mayer, P., Rittberger, V., \& Zürn, M. (1993). Regime theory: State of the art and perspectives. In V. Rittberger (Ed.), Regime theory and international relations (pp. 391-430). Oxford: Oxford University Press.

Miles, E. L., Underdal, A., Andresen, S., Wettestad, J., Skjærseth, J. B., \& Carlin, E. M. (Eds.). (2002). Environmental regime effectiveness. Cambridge, MA: MIT Press.

Mitchell, R. B. (2006). Problem structure, institutional design, and the relative effectiveness of international environmental agreements. Global Environmental Politics, 6(3), 72-89.

Mitchell, R. B. (2008). International environmental agreements database project (2002-08), version 2007.1. http://iea.uoregon.edu/, Accessed Oct 31, 2013.

Oberthür, S. (2001). Linkages between the Montreal and Kyoto protocols: Enhancing synergies between protecting the ozone layer and the global climate. International Environmental Agreements, 1(3), 357-377.

Oberthür, S. (2009). Interplay management: Enhancing environmental policy integration among international institutions. International Environmental Agreements, 9(3), 371-391.

Oberthür, S., \& Gehring, T. (Eds.). (2006). Institutional interaction in global environmental governance: Synergy and conflict among international and EU policies. Cambridge, MA: MIT Press.

Oberthür, S., \& Gehring, T. (2011). Institutional interaction: Ten years of scholarly development. In S. Oberthür \& O. S. Stokke (Eds.), Managing institutional complexity: Regime interplay and global environmental change (pp. 25-58). Cambridge, MA: MIT Press.

Oberthür, S., \& Stokke, O. S. (Eds.). (2011). Managing institutional complexity: Regime interplay and global environmental change. Cambridge, MA: MIT Press.

Olson, M. (1965). The logic of collective action-public goods and the theory of groups. Cambridge, MA: Harvard University Press.

Ovodenko, A., \& Keohane, R. (2012). Institutional diffusion in international environmental affairs. International Affairs, 88(3), 523-541.

Porter, G., \& Welsh Brown, J. (1996). Global environmental politics. Boulder, CO: Westview Press.

Pretty, J., \& Ward, H. (2001). Social capital and the environment. World Development, 29(2), $209-227$.

Rosendorff, P. B. (2005). Stability and rigidity: Politics and design of the WTO's dispute settlement procedure. American Political Science Review, 99(3), 389-400.

Rosendorff, P. B., \& Milner, H. V. (2001). The optimal design of international trade institutions: Uncertainty and escape. International Organization, 55(4), 829-857.

Ruggie, R. (1986). Continuity and transformation in the world polity: Toward a neorealist synthesis. In R. Keohane (Ed.), Neorealism and its critics (pp. 131-157). New York: Columbia University Press.

Selin, H., \& VanDeVeer, S. D. (2003). Mapping institutional linkages in European air pollution politics. Global Environmental Politics, 3(3), 14-46.

Shaffer, G. (2001). The world trade organization under challenge: Democracy and the law and politics of the WTO's treatment of trade and environment matters. Harvard Environment Law Review, 25(1), 1-93.

Shaffer, G., \& Pollack, M. A. (2010). Hard vs. soft law: Alternatives, complements, and antagonists in international governance. Minnesota Law Review, 94(3), 706-799.

Shaffer, G., \& Pollack, M. A. (2011). Hard versus soft law in international security. Boston College Law Review, 52(4), 1147-1241.

Simmel, G. (1950). Fundamental problems of sociology: Individual and society. In K. H. Wolff (Ed.), The sociology of Georg Simmel (pp. 3-79). New York: Free Press.

Skjærseth, J. B., Stokke, O. S., \& Wettestad, J. (2006). Soft law, hard law, and effective implementation of international environmental norms. Global Environmental Politics, 6(3), 104-120. 
Slaughter, A.-M. (2004). Sovereignty and power in a networked world order. Stanford Journal of International Law, 40(283), 283-327.

Slikker, M., \& van den Nouweland, A. (2001). Social and economic networks in cooperative game theory. Dordrecht: Kluwer.

Snidal, D. (1996). Political economy and international institutions. International Review of Law and Economics, 16(1), 121-137.

Spilker, G., \& Koubi, V. (2012). Why do countries participate in global environmental agreements?. ETH Zurich: Typescript.

Stokke, O. S. (2001). Governing high sea fisheries. The interplay of global and regional regimes. Oxford: Oxford University Press.

Ward, H. (2006). International linkages and environmental sustainability: The effectiveness of the regime network. Journal of Peace Research, 43(2), 149-166.

Ward, M. D., Stovel, K., \& Sacks, A. (2011). Network analysis and political science. Annual Review of Political Science, 14(1), 245-264.

Wasserman, S., \& Faust, K. (1997). Social network analysis: Methods and applications. Cambridge: Cambridge University Press.

Young, O. R. (1999). The effectiveness of international environmental regimes: Causal connections and behavioral mechanisms. Cambridge, MA: MIT Press.

Young, O. R. (2002). The institutional dimensions of environmental change: Fit, interplay, and scale. Cambridge, MA: MIT Press. 